\title{
COVID-19 pandemic: the effects of quarantine on cardiovascular risk
}

\author{
Anna Vittoria Mattioli $\mathbb{B}^{1} \cdot$ Matteo Ballerini Puviani $\mathbb{B}^{2} \cdot$ Milena Nasi $\mathbb{B}^{1} \cdot$ Alberto Farinetti $\mathbb{B}^{1}$
}

Received: 30 March 2020 / Revised: 16 April 2020 / Accepted: 22 April 2020 / Published online: 5 May 2020

(c) Springer Nature Limited 2020

\begin{abstract}
COVID-19 is causing a global pandemic with a high number of deaths and infected people. To contain the diffusion of COVID-19 virus, Governments have enforced restrictions on outdoor activities or even collective quarantine on the population. One important consequence of quarantine is a change in lifestyle: reduced physical activity and unhealthy diet. 2019 guidelines for primary prevention of cardiovascular disease indicate that "Adults should engage in at least 150 minute per week of accumulated moderate-intensity or 75 minute per week of vigorous-intensity aerobic physical activity (or an equivalent combination of moderate and vigorous activity) to reduce ASCVD risk." During quarantine, strategies to further increase home-based physical activity and to follow a healthy diet should be implemented. Quarantine carries some longterm effects on cardiovascular disease, mainly related to unhealthy lifestyle and anxiety. Following quarantine a global action supporting healthy diet and physical activity is mandatory to encourage people to return to good lifestyle.
\end{abstract}

\section{Introduction}

Quarantine and isolation are two measures that can prevent, or at least minimize, the impact of infectious disease outbreaks. In public health practice, "quarantine" refers to the separation of persons (or communities) who have been exposed to an infectious disease. "Isolation," in contrast, applies to the separation of persons who are known to be infected [1]. There are several examples of Government imposed quarantine or travel bans, i.e., at least 18 US states quarantined people returning from West Africa during the 2014 Ebola outbreak [1]. Now, COVID-19 infection is causing a global pandemic with a high number of deaths. By March 29, Italy reported 10,023 deaths (Italian Health Ministry, https://www.salute.gov.it/portale/nuovocorona virus/) [2]. To contain the diffusion of the COVID-19 virus, the Italian Government as well as others have enforced on the population. The previous experience of the SARS outbreak showed the efficacy of timely quarantine

Anna Vittoria Mattioli

annavittoria.mattioli@unimore.it

1 Surgical, Medical and Dental Department of Morphological Sciences related to Transplant, Oncology and Regenerative Medicine, University of Modena and Reggio Emilia, Modena, Italy

2 Istituto Nazionale per le Ricerche Cardiovascolari, University of Modena and Reggio Emilia, Modena, Italy and isolation measures [3, 4]. Quarantine is often an unpleasant experience: loss of freedom, uncertainty over disease status, and boredom can create dramatic effects. The potential benefits of mandatory mass quarantine need to be weighed carefully against the possible long-term negative effects on cardiovascular risk burden $[4,5]$.

\section{Quarantine and diet}

The main consequence of quarantine is a change in lifestyle and nutritional habits (Table 1). Nutritional habits will change due to reduced availability of goods, limited access to food caused by restricted store opening hours, and to a switch to unhealthy food. A recent review on the psychological impact of quarantine [6] reported negative psychological effects including post-traumatic stress symptoms, confusion, and anger. Having inadequate basic supplies (e.g., food, water) during quarantine was a source of frustration [7] and continued to be associated with anxiety and anger for 4-6 months following release [7, 8]. Due to anxiety of future food shortage, it is plausible that people will purchase packaged and long-life food rather than fresh food. This leads to weight gain and to a reduced intake of antioxidants. Oxidative stress and mild chronic vascular inflammation are part of the pathophysiology of hypertension and atherosclerosis [9]. Diets rich in antioxidant food (i.e., Mediterranean diet and Dash diet) are vascular protective. Several studies found that the Mediterranean diet is 
Table 1 What is known about quarantine and isolation.

What is known about quarantine and isolation

- Quarantine and isolation are efficacy in reducing diffusion of infection and prevent pandemic

- Quarantine and isolation are associated with anxiety, anger and stress

- Anxiety and stress are frequently associated with unhealthy lifestyle

- Quarantine induce a reduction of outside exercise and physical activity

- Stress as well as depression can induce people to eat and drink to feel better

associated with a reduction in incidence, prevalence, and mortality from coronary artery disease, cardiovascular disease, diabetes, and in all-causes mortality including cancer $[10,11]$. A systematic review on 7186 subjects (5168 subjects assigned to a Mediterranean diet), reported a significant reduction in central obesity with a Mediterraneantype diet [12]. Mediterranean diet is naturally low in sodium due to its low degree of processing, unlike processed foods (a term that covers all foods that have undergone manufacturing methods, including convenience foods and products like bread, cheese, and meat products) and is also rich in fruit and vegetables [13]. Diets rich in fruits and vegetables have several positive effects: known health benefits of high flavonol intake, potential increase in nitric oxide species, concomitant weight loss, reduction of blood pressure, and reduction of inflammatory markers [14, 15]. These beneficial effects are similar in men and women despite the fact that adherence to diet and healthy lifestyle is influenced by gender $[11,16]$.

Quarantine induces anxiety and stress. Torres and Nowson analyzed the relationship between stress and eating behavior and identified that people cope with stress by eating and drinking in an attempt to feel better ("stressrelated eating"). These stress-driven eaters and drinkers were more likely to eat unhealthy foods such as snacks, hamburgers, soda cola, and chocolate regularly and to drink wine and spirits more frequently. In addition, the lack of emotional support from friends and relatives was predictive of stress-driven eating and drinking behaviors [17, 18]. During quarantine, stress-driven eaters would easily switch from a healthy diet to unhealthy ones. This would affect cardiovascular risk mainly in high-risk patients.

\section{Quarantine and physical activity}

Together with the unhealthy diet, the reduction of physical activity will contribute to weight gain during quarantine. Regular physical activity is mandatory to maintain health status, and is associated with reduction in cardiovascular risk [11, 19]. The OMS suggests performing physical activity, such as walking, cycling, sports, dance, and yoga, in a manner that will prevent noncommunicable disease [20]. During quarantine the Italian Government prohibited the great majority of outdoor and social activities (e.g., going to the gym) resulting in a reduction of physical activity. Despite the guidelines to workout at home, only few subjects comply.

The reduction of physical activity will increase oxidative stress. Oxidative stress leads to apoptotic cell death of endothelial cells, reduces nitric oxide levels, increases activity of matrix metalloproteases and amplifies vascular inflammation, provoking vasoconstriction, LDL oxidation, and accumulation of foam cells [19, 21]. Oxidative stress is mutually linked to inflammation, often associated with an increased risk of endothelial dysfunction [21]. In addition, obesity is associated with elevated circulating levels of IL-6 and $\mathrm{TNF} \alpha$, which are subsequently decreased with weight loss. In obese subjects, adipose tissue becomes dysfunctional, promoting a pro-inflammatory, hyperlipidemic, and insulin resistant environment that contributes to cardiovascular disease [22].

It is well recognized that chronic physical activity attenuates oxidative stress in healthy subjects via the improvement of antioxidant enzyme capacities and inflammation via the enhancement of anti-inflammatory molecules [23]. The reduction of physical activity worsens cardiovascular risk by increasing cardiovascular risk factors burden.

\section{Quarantine and well-being}

The role of negative psychological factors-including depression, anxiety, and hostility - in the development and progression of cardiovascular disease is well established $[24,25]$.

By contrast, several studies have linked positive psychological characteristics with lower levels of traditional cardiovascular risk factors and decreased incidence of $\mathrm{CV}$ disease [26]. Prospective investigations of patients with existing CVD have shown that greater positive well-being is associated with reduced risk of secondary cardiovascular events and mortality [26, 27].

Positive well-being is thought to influence cardiovascular disease by (a) promoting adaptive physiological functioning, (b) motivating better health behaviors, and (c) buffering against the detrimental effects of stress on health $[26,28,29]$. These three pathways are interrelated and not mutually exclusive.

Positive well-being may act as a modifiable protective factor that could reduce the burden of CVD through its potential influences on lifestyle behaviors [24, 26-28]. People with higher positive well-being tend to have better 
health behaviors, including nonsmoking, greater physical activity, better dietary patterns, and lower incidence of sleep disturbances. It remains unclear whether positive well-being leads to better subsequent health behaviors or vice versa, however a strong relationship has been demonstrated. Positive well-being is thought to have multiple salutary effects during stress, such as reducing inflammatory and cardiovascular responses to acute stressors. Positive well-being also acts on cardiovascular function and cardiac autonomic control, reducing heart rate and blood pressure [24, 26].

\section{Effects of quarantine in the long-term period}

It is difficult to see the acute effects of quarantine on atherosclerosis. Nonhealthy lifestyle through increase of inflammatory status could trigger activation of preexisting plaques. We cannot exclude that changes in lifestyle persist after quarantine. In this case the risk of an economic crisis will maintain stress and anxiety in subjects, principally in those belonging to low socio-economic categories, leading to an increase in cardiovascular risk.

Following the Spagnola pandemic throughout 1918, a peak of cardiovascular events was reported. Such events manifest from 7 to 10 days after the emergence of influenza symptoms. In 1918, immediately after the end of the Spagnola epidemic, deaths caused by cardiovascular events had outmatched deaths from other causes, including superimposed pneumonia [30, 31].

\section{What must be done to prevent increase of obesity and of cardiovascular risk}

We think cardiologists need to be prepared to face the likely increase in obesity immediately after the end of the pandemic.

During quarantine we must promote physical activity at home. Little information is available on effects of homebased physical activity on chronic disease [32-34]. Despite physical activity being defined mandatory for cardiovascular prevention, guidelines do not contain home-based physical activity indications [35]. The "2019 ACC/AHA Guideline on the Primary Prevention of Cardiovascular Disease" recommended that "Adults should engage in at least 150 minute per week of accumulated moderateintensity or 75 minute per week of vigorous-intensity aerobic physical activity (or an equivalent combination of moderate and vigorous activity) to reduce ASCVD risk" (Class I LOE B-NR) or "for adults unable to meet the minimum physical activity recommendations, engaging in some moderate- or vigorous-intensity physical activity, even if less than this recommended amount, can be beneficial to reduce ASCVD risk" (Class IIa LOE B-NR) [35].
Table 2 Key point for managing patients after pandemic COVID-19 restriction.

Key point for managing patients after pandemic COVID-19 restriction

- Changes of nutritional habits: are there temporarily or persist long after the end of restriction?

- Changes in lifestyle including physical activity

- Stress and anxiety persistence

- Differences between men and women

- Number of cardiovascular events

The WHO has just released guidance to "Stay physically active during self-quarantine" in order to improve healthy behaviour during quarantin [36]. Today there are thousands of workout videos available on the Internet. The goal is to assist people perform these workouts independently on their own. A common observation is that even people who visit gym regularly find it difficult to perform all steps (body pose alignments) in a workout accurately. By continuously doing an exercise incorrectly may eventually cause severe long-term injuries [37].

After quarantine we need to reevaluate the cardiovascular risk in patients together with metabolic parameters including glycemic status. Patients also need to be evaluated by psychologist to early identify the persistence of anxiety and stress (Table 2). A global action supporting healthy diet and physical activity is mandatory to encourage people to return to good lifestyle. This action has to be stronger at a low socio-economic level where individuals will suffer to a higher degree from the restrictions.

Acknowledgements We would like to thank Mrs Janet Ann Carter for reviewing the paper. We thank everyone who is working to resolve the SARS-Cov-2 pandemic.

Author contributions MBP, MN, and AVM conceived of the idea at the basis of the article. AVM, MN, and MBP developed the different parts of the manuscript. All authors performed the final supervision. All authors contributed to and approved the final manuscript.

\section{Compliance with ethical standards}

Conflict of interest The authors declare that they have no conflict of interest.

Publisher's note Springer Nature remains neutral with regard to jurisdictional claims in published maps and institutional affiliations.

\section{References}

1. Parmet WE, Sinha MS. Covid-19-the law and limits of quarantine. N Engl J Med. 2020. https://doi.org/10.1056/NEJMp2004211.

2. Wu Z, McGoogan JM. Characteristics of and important lessons from the coronavirus disease 2019 (COVID-19) outbreak in China: summary of a report of 72314 cases from the Chinese 
Center for Disease Control and Prevention. JAMA. 2020. https:// doi.org/10.1001/jama.2020.2648.

3. WHO. Update 58-first consultation on SARS epidemiology, travel recommendations for Hebei Province (China), situation in Singapore. WHO. 2003. http://www.who.int/csr/sars/archive/2003_05_17/en/.

4. Giubilini A, Douglas T, Maslen H, Savulescu J. Quarantine, isolation and the duty of easy rescue in public health. Dev World Bioeth. 2018;18:182-9. https://doi.org/10.1111/dewb.12165.

5. Mattioli AV, Nasi M, Cocchi C, Farinetti A. COVID 19 outbreak: impact of the quarantine-induced stress on cardiovascular disease risk burden [published online ahead of print, 2020 Apr 30]. Future Cardiol. 2020. https://doi.org/10.2217/fca-2020-0055.

6. Brooks SK, Webster RK, Smith LE, Woodland L, Wessely S, Greenberg N, et al. The psychological impact of quarantine and how to reduce it: rapid review of the evidence. Lancet. 2020;395:912-20. https://doi.org/10.1016/S0140-6736(20)30460-8.

7. Blendon RJ, Benson JM, DesRoches CM, Raleigh E, Taylor-Clark $\mathrm{K}$. The public's response to severe acute respiratory syndrome in Toronto and the United States. Clin Infect Dis. 2004;38:925-31.

8. Jeong H, Yim HW, Song Y-J, Ki M, Min JA, Cho J, et al. Mental health status of people isolated due to Middle East respiratory syndrome. Epidemiol Health. 2016;38:e2016048.

9. Siti HN, Kamisaha Y, Kamsiaha J. The role of oxidative stress, antioxidants and vascular inflammation in cardiovascular disease (a review). Vasc Pharmacol. 2015;71:40-56.

10. Mattioli AV, Coppi F, Migaldi M, Scicchitano P, Ciccone MM, Farinetti A. Relationship between Mediterranean diet and asymptomatic peripheral arterial disease in a population of premenopausal women. Nutr Metab Cardiovasc Dis. 2017;27:98590. https://doi.org/10.1016/j.numecd.2017.09.011.

11. Mattioli AV, Sciomer S, Moscucci F, Maiello M, Cugusi L, Gallina S, et al. Cardiovascular prevention in women: a narrative review from the Italian Society of Cardiology working groups on 'Cardiovascular Prevention, Hypertension and peripheral circulation' and on 'Women Disease'. J Cardiovasc Med. 2019;20:57583. https://doi.org/10.2459/JCM.0000000000000831.

12. Bendall CL, Mayr HL, Opie RS, Bes-Rastrollo M, Itsiopoulos C, Thomas CJ. Central obesity and the Mediterranean diet: a systematic review of intervention trials. Crit Rev Food Sci Nutr. 2018;58:3070 84. https://doi.org/10.1080/10408398.2017.1351917.

13. Magriplis E, Panagiotakos D, Kyrou I, Tsioufis C, Mitsopoulou $\mathrm{AV}$, Karageorgou D, et al. Presence of hypertension is reduced by Mediterranean diet adherence in all individuals with a more pronounced effect in the obese: the Hellenic National Nutrition and Health Survey (HNNHS). Nutrients. 2020;12:853.

14. Głąbska D, Guzek D, Groele B, Gutkowska K. Fruit and vegetable intake and mental health in adults: a systematic review. Nutrients. 2020;12:E115. https://doi.org/10.3390/nu12010115.

15. Mattioli AV, Coppi F, Migaldi M, Farinetti A. Fruit and vegetables in hypertensive women with asymptomatic peripheral arterial disease. Clin Nutr ESPEN. 2018;27:110-2.

16. Sciomer S, Moscucci F, Maffei S, Gallina S, Mattioli AV. Prevention of cardiovascular risk factors in women: the lifestyle paradox and stereotypes we need to defeat. Eur J Prev Cardiol. 2019;26:609-10. https://doi.org/10.1177/2047487318810560.

17. Torres SJ, Nowson CA. Relationship between stress, eating behavior, and obesity. Nutrition. 2007;23:887-94. https://doi.org/ 10.1016/j.nut.2007.08.008.

18. Laitinen J, Ek E, Sovio U. Stress-related eating and drinking behavior and body mass index and predictors of this behavior. Prev Med. 2002;34:29-39. https://doi.org/10.1006/pmed.2001.0948.

19. Nasi M, Patrizi G, Pizzi C, Landolfo M, Boriani G, Dei Cas A, et al. The role of physical activity in individuals with cardiovascular risk factors: an opinion paper from Italian Society of Cardiology-Emilia Romagna-Marche and SIC-Sport. J Cardiovasc Med. 2019;20:6319. https://doi.org/10.2459/JCM.0000000000000855.
20. WHO. WHO global action plan on physical activity 2018-2030: more active people for a healthier world. Geneva: World Health Organization; 2018. Licence: CC BY-NC-SA 3.0 IGO.

21. Karbach S, Wenzel P, Waisman A, Munzel T, Daiber A. eNOS uncoupling in cardiovascular diseases-the role of oxidative stress and inflammation. Curr Pharm Des. 2014;20:3579-94.

22. Chait A, den Hartigh LJ. Adipose tissue distribution, inflammation and its metabolic consequences, including diabetes and cardiovascular disease. Front Cardiovasc Med. 2020;7:22. https://doi. org/10.3389/fcvm.2020.00022.

23. Mury P, Chirico EN, Mura M, Millon A, Canet-Soulas E, Pialoux V. Oxidative stress and inflammation, key targets of atherosclerotic plaque progression and vulnerability: potential impact of physical activity. Sports Med. 2018;48:2725-41. https://doi.org/ 10.1007/s40279-018-0996-z.

24. Sin NL. The protective role of positive well-being in cardiovascular disease: review of current evidence, mechanisms, and clinical implications. Curr Cardiol Rep. 2016;18:106. https://doi.org/ 10.1007/s11886-016-0792-z.

25. Kivimäki M, Steptoe A. Effects of stress on the development and progression of cardiovascular disease. Nat Rev Cardiol. 2018;15:215-29. https://doi.org/10.1038/nrcardio.2017.189.

26. Boehm JK, Kubzansky LD. The heart's content: the association between positive psychological well-being and cardiovascular health. Psychol Bull. 2012;138:655-91.

27. DuBois CM, Lopez OV, Beale EE, Healy BC, Boehm JK, Huffman JC. Relationships between positive psychological constructs and health outcomes in patients with cardiovascular disease: a systematic review. Int J Cardiol. 2015;195:265-80.

28. Folkman S, Moskowitz JT. Positive affect and the other side of coping. Am Psychol. 2000;55:647-54.

29. Ong AD. Pathways linking positive emotion and health in later life. Curr Dir Psychol Sci. 2010;19:358-62.

30. Collins S. "Excess mortality from causes other than influenza and pneumonia during influenza epidemics". Public Health Rep. 1932;47:2159-79.

31. Madjid M, Casscells SW. Of birds and men: cardiologists' role in influenza pandemic. Lancet. 2004;364:1309.

32. Hageman D, Fokkenrood HJP, Gommans LNM, van den Houten MML, Teijink JAW. Supervised exercise therapy versus homebased exercise therapy versus walking advice for intermittent claudication. Cochrane Database Syst Rev. 2018;CD005263. https://doi.org/10.1002/14651858.CD005263.pub4.

33. Mattioli AV, Nasi M, Coppi F, Gelmini R, Farinetti A. Relationship between socioeconomic status and asymptomatic peripheral arterial disease: a retrospective study. J Cardiovasc Med. 2020. (In press). Apr 3. https://doi.org/10.2459/JCM.0000000000000960. Online ahead of print.

34. Taylor JK, Buchan IE, van der Veer SN. Assessing life-space mobility for a more holistic view on wellbeing in geriatric research and clinical practice. Aging Clin Exp Res. 2019;31:43945. https://doi.org/10.1007/s40520-018-0999-5.

35. Arnett DK, Blumenthal RS, Albert MA, Buroker AB, Goldberger ZD, Hahn EJ, et al. 2019 ACC/AHA guideline on the primary prevention of cardiovascular disease: a report of the American College of Cardiology/American Heart Association Task Force on Clinical Practice Guidelines. Circulation. 2019. https://doi.org/10. 1161/CIR.0000000000000678.

36. WHO guideline. "Stay physically active during self-quarantine" (2020). www.euro.who.int/en/health-topics/health-emergencies/ coronavirus-covid-19/novel-coronavirus-2019-ncov-technicalguidance/stayphysically-active-during-self-quarantine.

37. Nagarkoti A, Teotia R, Mahale AK, Das PK. Realtime indoor workout analysis using machine learning \& computer vision. Conf Proc IEEE Eng Med Biol Soc. 2019;2019:1440-3. https://doi.org/ 10.1109/EMBC.2019.8856547. 